\title{
Tissue Analysis as a Nutrient Management Tool for Bahiagrass Pastures ${ }^{1}$
}

\author{
M.L. Silveira, J.M. Vendramini, L.E. Sollenberger, C.L. Mackowiak, Y.C. Newman²
}

\section{Principles of Tissue Analysis}

While some plant nutrient deficiencies can be easily identified based on visible symptoms, others may not produce any specific foliar symptoms other than reduced yield. In this case, plant analysis can be useful for diagnosing nutrients that are limiting optimum crop production. Although the concept of using plant analysis for nutrient diagnostics is not new, there is growing interest in using nutrient concentration in plant tissue as a tool to manage soil fertility in bahiagrass pastures in Florida. This is due in part to the inability of soil tests to accurately predict forage nutrient requirements. While soil tests typically examine nutrient levels in the upper 6 inches of the soil profile, plant analysis can integrate the nutrient pools present at the various soil depths. Because of extensive plant root systems, plant analysis is believed to better assess the overall nutrient status of forage crops and also reveal imbalances among nutrients that may affect crop production.

Plant analysis involves the determination of nutrient concentrations in a sample from a particular part or portion of a crop, at a specific time or stage of development. Since various factors can influence crop tissue concentrations, tissue tests should be used with some restraint and in conjunction with a routine soil testing program. Nutrient concentrations in the plant are not static and may vary within parts of the plant, time of the year, and among forage varieties and species. The factors that affect plant nutrient concentrations include (1) physiological maturity of the stand, (2) sampling procedure and parts of the plant that are sampled, (3) sample preparation and handling, and (4) environmental conditions, such as soil moisture and temperature. Thus, it is essential that samples are properly collected and handled prior to analysis. The interpretation of a plant analysis report requires a through understanding of the factors that may influence the test results. Therefore, great care should be taken when considering forage fertilization programs based on tissue analysis.

The basic principle involved in plant analysis interpretation is that yield will be limited at a critical nutrient concentration for each specific crop. The basic relationship between nutrient concentration and yield is shown in Fig. 1. The critical level, defined as

1. This document is SL252, a fact sheet of the Soil and Water Science Department, Florida Cooperative Extension Service, Institute of Food and Agricultural Sciences, University of Florida. Original publication date October 2007. Visit the EDIS Web Site at http://edis.ifas.ufl.edu.

2. M.L. Silveira, assistant professor and J.M. Vendramini, asssistant professor, Range Cattle REC - Ona, FL; L.E. Sollenberger, professor and Y.C. Newman, assistant professor, Agronomy Department, Gainesville, FL; and C.L. Mackowiak, assistant professor, North Florida REC - Quincy, FL, Florida Cooperative Extension Service, Institute of Food and Agricultural Sciences, University of Florida, Gainesville, FL 32611. 
the nutrient concentration range in the plant sample below which crop yield is significantly reduced, varies among forage crops. For most forage crops, however, there is a "critical range" associated with yield reduction rather than a single value.

Realistically, a number of factors may affect nutrient concentration and crop yield, which makes it impossible to define a specific optimum nutrient concentration in the plant.

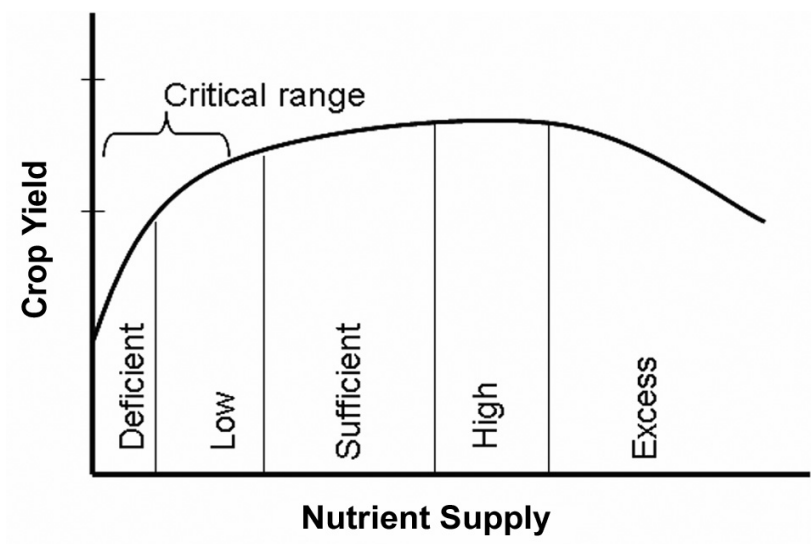

Figure 1. Relationship between nutrient supply and crop yield.

The "critical range" refers to the nutrient level below which significant yield reduction is expected. Although "significant" yield reduction is open to interpretation, typically $10 \%$ is used for many crops. On the other hand, if a nutrient is either at the sufficient or high range, minimal or no yield response is expected due to fertilization.

\section{Tissue Sampling and Handling}

Sample collection and preparation are important steps for ensuring accurate tissue analysis results. Similarly to soil testing, tissue samples must be representative of the field. The number of plants to sample in a specific area will depend on the general conditions of plant vigor, soil heterogeneity, and forage management. A truly representative sample should be taken by sampling a large number of plants so that the sample represents the field. Collect at least 1 ounce ( $30 \mathrm{~g}$ ) of fresh material (Fig. 2). Sampling is not recommended when plants are injured by insects and diseases. To avoid contamination, plants should not be sampled soon after spraying pesticides or herbicides. Care should be taken to minimize soil contamination on the sampled plant material. In addition, plants should not be sampled under temperature or moisture stress. Preferably samples should be collected during a time of the day when climatic conditions are mild, generally early to mid-morning or early evening.

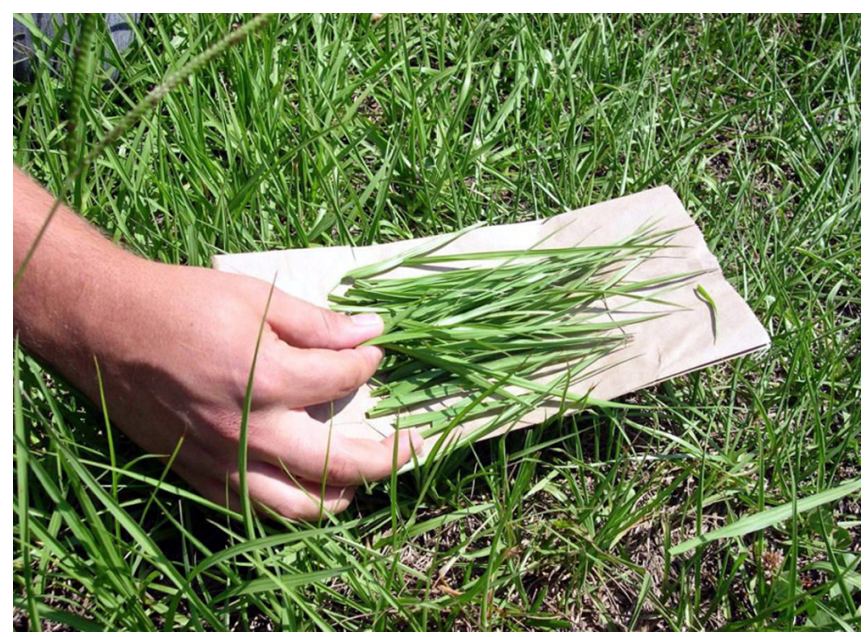

Figure 2. Approximately 1 ounce (30 g or a handful) or more of leaf sample representing the field should be collected and placed in a paper bag.

The plant part, maturity stage and time of sampling are also important factors that can affect plant nutrient composition. Forage grasses and hay fields should be sampled prior to seed head emergence or at the optimum stage for forage utilization (Jones et al., 1971). As the plant matures, nutrient concentrations decline, so it is critical that plants are sampled at the proper stage of maturity. Care should be taken to select the plant part that accurately reflects the nutrient status of the plant. The four uppermost leaf blades should be sampled (Fig. 3). Do not sample seeds since they are not useful for assessing nutrient status of forage crops and may introduce large errors in the report interpretation. If deficiency symptoms are suspected, plants showing these symptoms should be sampled and analyzed separately from "normal" or healthy appearing plants.

After sampling, tissue should be placed in properly labeled paper bags and sent immediately to a reputable laboratory for analysis. Avoid plastic bags because they can hold heat and moisture. The same precautions used for collecting the plant material should be used to handle the samples. Because fresh plant material may start decomposing shortly after collection, it is important that plant material be sent 


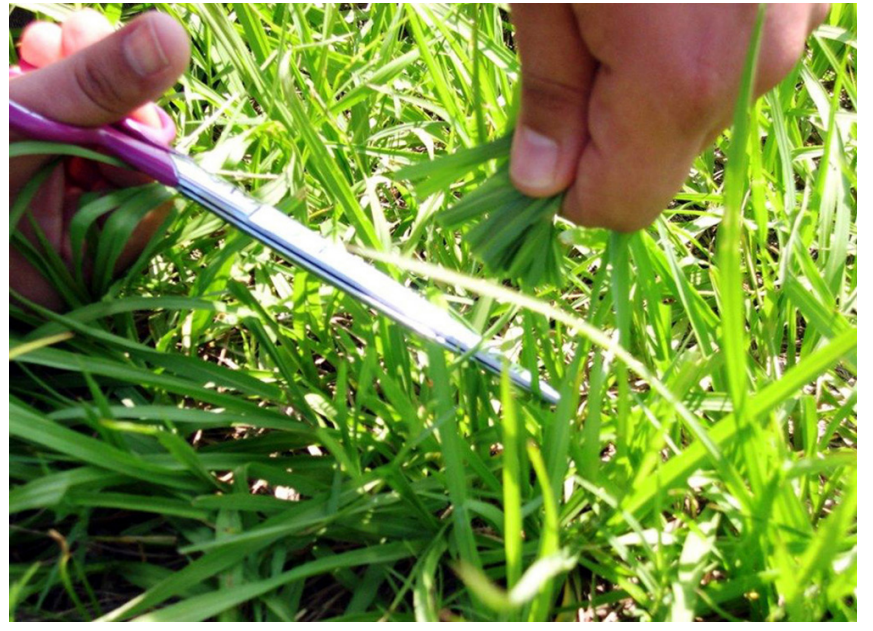

Figure 3. Gathering young bahiagrass leaf blades using scissors.

to the laboratory as quickly as possible. Prior to transporting the samples to the laboratory, plant material should be stored in a refrigerator at $41^{\circ} \mathrm{F}$ (or $\left.5^{\circ} \mathrm{C}\right)$.

\section{Tissue Analysis Interpretation}

Critical concentrations of $\mathrm{N}, \mathrm{P}$, and $\mathrm{K}$ in bahiagrass forage are shown in Table 1 . Tissue analysis has been recently incorporated into the revised IFAS fertilizer recommendations as a management tool to guide proper $\mathrm{P}$ fertilization in established bahiagrass pastures. According to the revised IFAS recommendations, tissue analysis should be performed when soil tests very low or low in $\mathrm{P}$. Assuming the soil $\mathrm{pH}$ is within the optimal range for bahiagrass (around 5.5) and the tissue $P$ concentration is below the critical concentration of $0.15 \%, \mathrm{P}$ fertilization is expected to improve bahiagrass production. Recommended $\mathrm{P}$ application rates vary from $25 \mathrm{lb}_{2} \mathrm{O}_{5} / \mathrm{A}$ for the low- and medium-N input options (50 and $100 \mathrm{lb}$ N/A, respectively), up to $40 \mathrm{lb}_{2} \mathrm{O}_{5} / \mathrm{A}$ for the high-N option (160 lb N/A).

Table 1. Critical concentrations of $\mathrm{N}, \mathrm{P}$, and $\mathrm{K}$ in bahiagrass tissue.

\begin{tabular}{|cc|}
\hline \hline Element & $\begin{array}{c}\text { Critical concentration } \\
(\%)\end{array}$ \\
\hline $\mathrm{N}$ & $<1.5$ \\
$\mathrm{P}$ & $<0.15$ \\
$\mathrm{~K}$ & $<1.2$ \\
\hline \hline
\end{tabular}

\section{Future Directions}

Similar to soil testing, plant analysis is an evolving process and our understanding needs to be updated as research results become available. Current data on critical nutrient concentration in bahiagrass should be considered preliminary and subject to modification as more science-based information becomes available. The balance among the various essential nutrients as well as the effects of bahiagrass varieties, soil characteristics, and management practices need to be fully explored in order to establish critical nutrient criteria for bahiagrass pastures in Florida. Nevertheless, from both agronomic and environmental perspectives, plant tissue analysis has potential to be a useful diagnostic tool for developing nutrient management programs that predict when crops need additional nutrients while avoiding negative impacts on the environment. 